\title{
Body, skill, and look: is bodybuilding a sport?
}

\author{
István Aranyosi ${ }^{1}$
}

Published online: 3 June 2017

(C) Springer Science+Business Media Dordrecht 2017

\begin{abstract}
I argue that bodybuilding should not qualify as a sport, given that at the competition stage it lacks an essential feature of sports, namely, skillful activity. Based on the classic distinction between Leib (the lived body) and Körper (the objective body) in phenomenology, I argue that bodybuilding competition's sole purpose is to present the Körper, whereas sports are about manifestations of Leib. I consider several objections to this analysis, after which I conclude that bodybuilding is an endeavor closer to both beauty competitions and classical sculpture rather than to any other known sports.
\end{abstract}

Keywords Skill · Sport · Phenomenology Sartre $\cdot$ Lived body

What counts as a sport has long been an issue of much controversy over the last few decades. For instance, Sports Accord, the largest international organization comprising all Olympic and Non-Olympic worldwide sports federations, has been working on a set of criteria for what counts as a sport, so that an official and widely agreed upon list of recognised sports could serve as the standard in this domain. Bodybuilding is, of course, on this list, and it is universally recognised as a sport. It has a venerable history, going back to late nineteenth Century England, when it was first practiced and promoted by Eugen Sandow, who would also be the one to organise the first professional competition in 1901, at the Royal Albert Hall, London. Then, from the 1970s on, bodybuilding was to become a world sensation, receiving wide publicity via Hollywood (in movies like Pumping Iron and Conan the Barbarian) and the Mr. Olympia international competition, creating successful business around nutrition supplements, and producing a few iconic figures, such as Arnold Schwarzenegger, Lou Ferrigno, or Dorian Yates.

István Aranyosi

istvanaranyosi@gmail.com; http://istvanaranyosi.net/

1 Department of Philosophy, Bilkent University, Ankara, Turkey 
It is thus very likely a thankless job to try to show that bodybuilding is not in fact a sport. Eventually, however, some philosopher must do the dirty job... What I will argue for is that there is something about bodybuilding that makes it art-like, but not sportlike, hence, it should rather qualify at best as an art form rather than as a sport. Potentially, the discussion could also be developed in the future into a more general framework for understanding what sport or sport-likeness would have to exhaustively involve as conceptual elements.

\section{The main argument: The goal of bodybuilding is not skilful activity}

Given the impressive diversity of currently recognised sports, the notion of a sport might look more like at most a family resemblance based concept, like that of a game, which Wittgenstein convincingly characterised along those lines. ${ }^{1}$ However, beyond this diversity we can safely identify a common thread: sports involve the goal of achieving relative excellence in some skilful activity. It involves trying to become better in performing some non-trivial task. In officially recognised mind games, such chess or bridge, the skills are essentially mental, whereas in the overwhelming majority of sports it is essentially physical. I will focus on physical sports since if it is a sport, bodybuilding falls into this category.

First, it is intuitive that sports are essentially active rather than passive. It would be hard to convince SportAccord to recognise sleeping or mere motionlessness ${ }^{2}$ competitions. Second, it seems to involve skill, which is activity that is supposed to overcome some challenge. There are, then, levels of manifesting the skill, according to which the performers of the sport will be judged and awarded. Third, there is an element of competition, at least to professional sports. Even if the sport is solitary both during the training period and when practiced for evaluation of the performance, it is implicit that the evaluation of the performance involves comparison with other performers, hence, we have. e.g., rankings and world records for 100-m sprint, or half-marathons, etc. Competition is present always, if not always relative to someone else, at least relative to one's own earlier self. The desire to become better at $\mathrm{X}$ seems to imply the desire to become better than Y.

Let us now turn to bodybuilding. Like in other sports, in bodybuilding there is a training period and a competition period. You train to become more competitive, so when the big day of competition comes, you can perform at your best and get judged and awarded accordingly. In all sports the training period comprises a mix of exercises some of which will be exactly the kind of performance that is expected in the competition. Things are no different in bodybuilding. The training consists both of non-competitional exercises, such as weight training and cardio training, and flexing and posing (in a mirror, for example), which is what you are supposed to do at the competition, in front of the jury. Where bodybuilding comes apart from other sports is precisely the performance evaluation criteria.

\footnotetext{
${ }^{1}$ Indeed, philosophers of sport have been skeptical about any attempt to define sport, cf. McBride 1975, Morgan 1977.

${ }^{2}$ I say mere motionlessness, because I can imagine sports where one needs to stay motionless against some mechanical force, hence, involving a real skill of resistance.
} 
What is judged in a competition is the general appearance of your body as far as your skeletal muscular system is concerned. This complex quality is thought to emerge from three component qualities of your muscular system: mass, proportion, and definition and vascularity. Bodybuilders typically use a calorie rich diet in the period when they build mass, then, closer to the competition, they reduce calorie intake in order to lose fat, and dehydrate in order to increase muscle definition and the appearance of vascularity. What is ultimately evaluated in the competition is not an activity or skilful excellence; you are judged not by what you $d o$ and how well you $d o$ it, but by what you are or have to show. This doing/being duality maps quite smoothly onto an important and intuitive distinction in phenomenology of the body, that between Leib (the lived body) and Körper (the body as an object). ${ }^{3}$ German language is especially suited for distinguishing these two aspects of the body, as the lived body is not the kind of body one has, but the kind one is (Körperhaben - to have a body), whereas the body as object is the kind one has (Leibsein - to be a body). The lived body is the body as it figures in our daily active involvement with the world, thus being in excess of what we are consciously aware of, or at least of what we consciously attend, or thematise (Gallagher 2005, ch. 1). ${ }^{4}$ The body as an object is the body as an intentional object of one's perception of it; in this, one's own body is no different from any other body in the external world.

My basic argument, then, is that since bodybuilding is a purely a "Körper-telic" activity, or, to use a Sartrean theme, since it is for the sake of The Look, ${ }^{5}$ it should not qualify as a genuine sport, as that would require Leibsein essentially as a goal, namely the manifestation of some physical skill. Since the element of skilful activity is essential to professional sports, bodybuilding should not be considered a sport. Rather, as I will argue after I go through some objections, it should be placed somewhere between beauty contests and classical sculpture.

So, first, here are some objections to consider.

\section{2 "The is a lot of activity involved in bodybuilding, during both the training and the competition period"}

It is true that there is a lot of activity in bodybuilding during training, some of which coincides with the activity specific to some sports during the competition period. Weight training exercises have components that coincide with some competition tasks in powerlifting and in Olympic weightlifting. The problem is, however, that in bodybuilding competitions your training, though normally correlated with your actual performance in the competition, is not graded at all. From the point of view of the competition how much you are trained is irrelevant and usually not known. If you are

\footnotetext{
3 The distinction was first put forward by German anthropologist Helmut Plessner (Krüger 2010), and subsequently adopted by well-known phenomenologists and existential philosophers, such as Maurice Merleau-Ponty (1962) and Jean-Paul Sartre (1943).

${ }^{4} \mathrm{Cf}$. Gallagher $(2005$, ch. 1) on body schema as opposed to body image; I will come back to this point in the last section of the paper.

${ }^{5}$ Sartre, in, Part 3, chapter 1 of Being and Nothingness, offered an extensive discussion of how awareness of oneself as a subject as well as intersubjectivity arise from one's awareness of The Look, that is, of being stared at by another subject. I will come back to this phenomenon in the last section of the paper.
} 
gifted with the right genetics, it might well happen that you perform much better than someone who trained a lot more than you; the jury does not care about your training efforts per se, except to make sure you were not using banned substances for muscle growth. The exercises performed during training certainly qualify as elements of sport, but, unfortunately, they don't make it to the competition stage whatsoever. Now, of course, it is true for most other sports that training itself does not get to be evaluated, but my point is that in other sports elements of training make it to the competition stage as manifest parts of the active process that leads to the desired result. Although these parts of the process are not themselves evaluated, only their end result, they are necessary in order to achieve the desired result - they are "part of the game". To offer a simple example, in marathon running it is ultimately one's time performance that gets evaluated, but in order to complete the marathon in a certain amount of time, it is necessary to actually run through the whole period, to perform what otherwise is an important component of marathon runners' standard training. The marathon itself, as a competitive event, consists of both the running, which is skilful, and the crossing of the finish line. By contrast, the bodybuilding competition consists of merely crossing the finish line.

There is also activity, the argument goes, during competition, namely, flexing your muscles and posing. The problem is, again, that, although how well you flex is causally correlated with how well built you appear to the eyes of the jury, it is not part of the complex quality itself of looking well built. The jury does not grade your flexing abilities per se, but the visual result of the flexing events. An analogy with house building is, I think, appropriate: when the question is how well-built a house is, we are looking at the final product, the house, and not at the process by which it got built. As for posing, again, contrary to what the continuous form of the verb might suggest, being good at posing means being able to end up in good poses, whatever "good" means in the context. ${ }^{6}$ A pose is a static event, a static appearance of one's body, not an activity. A good pose in bodybuilding is a static presentation of the body that exposes the details of one's musculature. It could be objected at this point that the static/ dynamic distinction is orthogonal to the issue of whether one's body performs posing or exhibits embodied skill. ${ }^{7}$ More to the point, the category of dynamic posing seems to make perfect sense, as in dance, which is why dance tends to be categorized under art rather than under sport. I admit that there is no incoherence in the idea of dynamic posing, but the reason why this is so has no effect on my argument. The way I see dynamic posing is that a certain dynamic performance, consisting of a series of movements, such as a dance performance, could be viewed and possibly enjoyed in two distinct ways: (i) in a purely spectatorial, detached fashion, where it is rather the Körper in motion that is admired, and (ii) in an empathetic, intercorporeal (MerleauPonty) fashion, where the spectator is to a certain extent corporally engaged with the performer. As a matter of fact, I think these two ways of enjoying a dance performance get intertwined in our actual enjoyment of, say, dance performances, though I also think that (ii) is more natural, because it is automatic and non-conscious whereas (i) is more artificial, and probably requires some more conscious control (see below the discussion

\footnotetext{
${ }^{6}$ For instance, interesting, aesthetically pleasing, expressive, depending on the purpose of the pose, as in photography, modeling for painting or fashion shows, or beauty contests.

${ }^{7}$ Many thanks to an anonymous referee for pushing me on this point.
} 
of mirror neurons). Turning back to my argument, even if we accept that dynamic posing is a real phenomenon, this does not change the fact that in bodybuilding posing it is hard to see how the intercorporeal, empathetic, automatic and engaged aspect of enjoying the performance would be present.

So neither flexing, nor posing should count as making a difference when it comes to the point that excellence in bodybuilding is not about activity.

\section{3 "At the deeper, neural level, there is no difference between powerlifting and bodybuilding: Both consist of voluntarily induced motor nerve fibre recruitment"}

Strength training consists of a set of various exercise types that, over time, have been observed to increase muscular strength in the trainee. Though at the observable, phenomenal level strength and endurance are measured straightforwardly, for instance, in terms of maximum one repetition weight lifting capacity (strength) and maximum number of repetitions of submaximal weight lifting over some duration (endurance), at the level of the neural and neuromuscular events there are several ways to understand and hence measure strength (Enoka 1988). However, on all accounts it appears essential that properties of motor unit (that is, motor nerve fibre) recruitment during action are evaluated, for instance, in terms of activation speed, force-length relathionship, length-tension relationship, and maximum intrinsic speed (Hodson-Tole and Wakeling 2009; Wakeling et al. 2012).

In powerlifting competitions, referees evaluate strength, and strength is reducible to certain properties of the neuromuscular system. Since at the neural and neuromuscular level motor fibre recruitment is ultimately shared by, say, powerlifting competitions and bodybuilding competitions, if the former counts as skilful activity, and hence as a sport, the latter should count too. Or so the argument goes.

In response, we should first note that the activity evaluated in powerlifting by direct observation coincides with the activity that occurs simultaneously at the level of the supervenience or reduction base, namely, at the neruromuscular level. Not so in bodybulding; fiber recruitment is rather a cause of what is evaluated rather than its constitutive process. Now, we could create a type of sport close to bodybuilding, call it 'precision flexing', in which it is the fibre recruitment that is supposed to occur in a skilful manner; for instance, a sport in which, instead of, or in addition to, showing muscle mass and definition the performer would have to contract the muscles in a very precise and skilful way, thus showing high control of clearly isolated and even small muscle groups, and be evaluated according not only to how the muscular system appears, but also on how certain parts of it are caused to appear in certain precise ways. But, as it stands, bodybuilding competitions only evaluate the static looks that are effects of the muscular contractile processes.

Second, in powerlifting and Olympic weightlifting contractile properties of muscles are evaluated in the context of an obstacle (a weighty object), hence it is not merely contraction as such that counts but contraction despite resistance. In bodybuilding, on the other hand, there is no resistance to one's muscular contractions. It is then arguably still within the concept of a skill to contract the muscle against non-trivial resistance, 
whilst contraction with no resistance does not look like a good candidate to be included in the category of skill.

Finally, if we went down that road, and assumed that it is muscular contraction that is ultimately evaluated, we would obtain the ridiculous conclusion that bodybuilding is a kind of powerlifting with no weights, and that.

\section{4 "Bodybuilding is a long process that requires conscious effort in the service of some long term physical goal, thus no different from how skills are developed"}

We are not born with skills, but we are born with the capacity to develop a range of skills. Manifestations of skill consist of exhibiting great ease in performing the relevant non-trivial task. Before the skill is fully developed there is need to consciously focus on the task, repeat its execution, correct its errors, find new strategies to achieve various critical goals. However, the sign that the skill is close to being fully developed is exactly the opposite: performing the task does not require conscious focus any more, but happens automatically and with great precision. In fact, as it is by now confirmed countless times by experience, for an expert in a field of activity that involves skill, focused attention on one's performance of the task would disrupt the proper execution of it, a phenomenon known as "choking" (Beilock and Carr 2001; Beilock et al. 2002; Cappuccio 2015). ${ }^{8}$ This is true in sports as well as in, say, playing an instrument, or even in cognitive tasks (Dreyfus 2012, Noë 2012: ch. 6). ${ }^{9}$

Now, the objection to my argument to the effect that bodybuilding is not a sport is that it does seem as though the long and painful training period in this competitive activity is no different from the long and painful practice period in, say, developing piano playing skills. A bodybuilder will typically have to focus on plenty of variables, such as training times and duration, muscle groups to be developed, strength acquisition, cardio training necessities, nutritional factors, sleep and rest periods.

The bodybuilder deserves, of course, credit and praise for his/her enormous work in creating a body that can compete on stage. My argument is not that bodybuilding is a trivial activity; it is rather that the physical skill that we admire in other sports competitions does not seem to be part of what a bodybuilding competition is about. There is a lot of skilful activity in training, indeed, as it overlaps with some competition tasks of other sports. There is also knowledge involved, both of one's own body and its capacities to develop and of other fields, such as nutrition science. But the fact remains that in the competition these skills are missing.

\footnotetext{
${ }^{8}$ Though not everyone agrees. More recently, philosophers such as Ellen Fridland (2014a, 2015) and Barbara Montero (2010) have convincingly argued that skilled behavior in fact requires some form or other of conscious, even intelligent control. Not much depends, for the purposes of this paper, who is right since, if I am right, bodybuilding (the competitional stage) is far removed from the cases of highly skilled behavior that these authors consider.

${ }^{9}$ It is worth noting that whereas in skilled performances there is a possibility of choking, in bodybuilding competitions this is excluded since, arguably, it is precisely attentional focus on the feedback from muscle fibers, tendons, and skin receptors that help a good, complete flexing performance. In other words, focusing on one's flexing helps this performance.
} 
Second, if the objection is that what gets implicitly evaluated in a bodybuilding competition is rather the long and skilful training of the competitor, because it is ultimately that which leads to the competitive body appearance, then it is worth noting that there is an important difference in the process of skill acquisition in other sports and the process of building up a physique. The difference lies in the kind of nervous system components that are involved in each. In physical skill acquisition the essential role is played by the motor system, whereas in anything that is essential to building up a physique it is the autonomic nervous system, the part of the nervous system responsible for vegetative functions, such as breathing, sweating, digestion, and so on. What gets causally controlled and manipulated via exercise in the training period is an autonomic function, namely muscle growth. ${ }^{10}$ To promote muscle growth could hardly count as a skill since it is no more than eliciting a completely automatic hormonal and an autonomic nervous system reaction to mechanical stress on the muscle fibres.

\section{5 "What is common and essential to all sports is the goal of overcoming a challenge"}

Finally, one could object to skill being the essential, common element of sports. Instead, sport could be considered as simply the endeavour to overcome some nontrivial challenge to the human body, or to the human mind in mental sports. The essence of sport is, according to this view, then, to push the limits of the human body or mind. The challenge in bodybuilding would then be to generate muscle hypertrophy, which is a way of pushing the boundaries of human muscle development.

There are two answers to this line of thought. First, overcoming a challenge is too general and hence it is at most a necessary condition on what should count as a sport. Otherwise, any challenge to the human body should be made the basis of a sport; for instance, one could develop a strong stomach so as to digest all sorts of rough organic materials, which normal people would not be able to. Yet, intuitively, "hyperdigestion" should not count as a sport. ${ }^{11}$

Second, if we have a look at actual sports, we notice that the challenge that is overcome os by no way some extreme, alien, super-human-like feature. Running, for example, is an activity that any healthy human subject is able to perform. So the challenge is not, in effect, to perform the activity, but to raise the quality of that performance along various measures; in running, it could be speed or endurance over time. Muscle hypertrophy, on the other hand, is not a state of the muscular system that any healthy subject is supposed to exhibit. It is either an anomaly, or a side-effect of training for some sport or other. In this way, muscle hypertrophy does not seem to fit the nature of challenge that all other sports are built on.

\footnotetext{
${ }^{10}$ No less so the more specifically competition linked dehydration and fat burning processes.

${ }^{11}$ One is reminded of Franz Kafka's short story "A hunger artist", which I interpret as an irony vis-à-vis such extensions of the concept or art that would include some trivial bodily function (here feeding and hunger) raised to an extreme level implementation, or lack of it thereof.
} 


\section{What kind of endeavour is bodybuilding?}

Ironic as it sounds, bodybuilding is the least embodied of currently recognized sports. Let me explain. When using the term 'embodied', philosophers involved in the embodied mind movement refer to the understanding of embodiment as Leibsein, not Körperhaben. It is the body schema rather than the body image that plays a foundational role in the whole project of embodied philosophy of mind. Bodybuilding, on the other hand, is the specialization in The Look, par excellence. When we watch and admire sportspeople, our focus is never the body among other bodies, but the lived body of the performer. Mirror neurons (Rizzolatti 2004) are witness to this; we do not merely observe and thematise, but resonate with the performer. It is part of why watching sports is pleasant. Bodybuilding is specialized in exhibiting the body as an object; it would be good, of course, if we there were empirical studies on this, but I submit that watching bodybuilding competitions is very different from watching, say, swimmers compete, in terms of how much mirror neuron involvement is present.

In a Sartrean key, bodybuilding appears as the quintessential (self)objectifying professional activity. It is an endeavour with the sole goal of conformity to the gaze of the Other; in this case, the Other is the group of judges and the spectators. Compare it to, say, sprint racing, where the goal or meaning is not to correspond to the expectations of the gaze of another, but rather the performance itself, the speeding up, the pace, etc. Sartre's discussion of the gaze as a medium of hetero- and auto-objectification and awareness of one's body as an object (being-in-itself, in Sartre's terminology), on top of one's self-awareness as a subject (being-for-itself), has had an enormous impact on various subdisciplines of philosophy, especially on feminism, where the place of the female body in contemporary consumer society has been analysed in Sartrean terms, as an objectified item whose sole role is to conform to the male gaze (e.g. Murphy 1999). The world of fashion and beauty contests are the textbook examples of when this existence for the gaze is formalized, institutionalised, normalised. In this aspect bodybuilding is, then, closer to beauty contests than to sports. ${ }^{12,13}$

On a more positive note, I also think bodybuilding is closer to the arts, more exactly, to classical sculpture, than to sports. It is a form of sculpture in a very difficult medium - the human living muscular system - and with extremely limited possibilities of expression, hence it deserves admiration and respect. Indeed, sculpture, especially classical one, is quintessentially a form of presenting a body for The Look, for conscious thematization. The only difference is that in classical sculpture the bodies are lifeless, whereas in bodybuilding they are alive;

\footnotetext{
${ }^{12}$ Though, to be fair, I do think beauty contests deserve more to have been considered a sport, given that there is a lot more skill involved in them than in bodybuilding competitions. It is hence even more paradoxical, or unfair, that beauty contest are not recognized as sports, while bodybuilding is.

${ }^{13}$ A further argument that bodybuilding is not a lived-body activity is worth noting here. Obsessive preoccupation with muscle mass is a pathology connected to the world of bodybuilding, leading to selfinjury and psychosis (Hameed et al. 2016), and it is in many ways a kind of reverse anorexia nervosa, a condition in which the subject becomes obsessively preoccupied by the goal of losing weight. As pointed out by Dorothée Legrand (2010: 194): "anorexics seek the preservation of their body-as-subject by destructing their body-as-object", which means that the object of obsessive attention in anorexia is the Körper. By analogy, then, since excessive bodybuilding activity is the mirror image of anorexia, bodybuilding is truly an activity directed to the body image rather than to the body schema or anything related to the lived-body.
} 
yet, the fact that in bodybuilding they are alive is really secondary, given that it is not the Leib aspect of the body that plays the essential role when it comes to competition and evaluation.

I would like to end by putting the above discussion, which, admittedly, is quite narrowly focused, in two larger theoretical contexts, namely, that of the wellestablished field of performance psychology and that of the currently emerging field of performance philosophy. ${ }^{14}$ Performance psychology deals with psychological aspects related to the goal of achieving peak performance, especially in sports (Williams 1993), whereas performance philosophy rather focuses on art performance, ${ }^{15}$ and tries to discover its philosophical aspects. In other words performance psychology focuses on how skill is deployed "in the field", while performance philosophy on how it is deployed "on stage". These are two ways of looking at skill, and, if what I argued before is correct, only the former is truly about embodied skill; the latter, in effect, is more about expressive skill, which is typical of arts or art-like performances. If my arguments above seem too Manichean, one could rather think about the issue of sportlikeness and art-likeness on a continuum, and judge various performance types along those lines. Dance and music performance are good examples to illustrate this continuum, I think.

There are many types of dance performance, and each of them could be viewed as a combination of embodied skills and expressive skills. Both involve the body, obviously, but in different ways. Embodied skills, or Leib-skills, involve the body as lived entity, and hence induce in both the performer and the audience a kind of active engagement, expressive skills, or Körper-skills, rather present the body as a body, and hence the motion, at least on the part of the audience, is not lived but admired from a purely spectatorial view. Arguably, classical ballet is closer to the Körper extreme of this spectrum, as it is the artistic expression through bodily motion that it is usually appreciated for, while, say, Lindy Hop dance is closer to the sporty, Leib side of the spectrum.

Music performance is also interesting, and in this case the two types of performative aspects, the sport-like and the art-like, truly come apart. Take, for instance, virtuoso instrument playing, like piano. One and the same performance can be enjoyed as a showcase of high technical skill, manifested through the finger motions, and as expressive excellence manifested through the aural effects of those motions. In other words, the sport-like aspect is bodily in nature, whereas the art-like aspect is auditory. Watching a dazzling virtuoso piano performance by, say, Boris Berezovsky, one can't help but be captured, moved, and engaged by the incredible mechanical skill showcased on the keyboard, but also sucked into the auditory experience with its highly expressive features.

Bodybuilding could, then, also be thought along these lines, placed on this spectrum, and, if I am right, it would clearly occupy a place much closer to the art-like side of performance.

\footnotetext{
${ }^{14}$ Thanks to an anonymous referee for this suggestion.

${ }^{15}$ Since performance philosophy is an emerging field, there is no current agreement on anything like a definition, or a gloss. However, there are prgramatic discussions (e.g. Kirkkopelto 2015) where the focus on art performance and, more narrowly, on performance arts is present.
} 
Acknowledgments I wrote this paper during my research fellowship at the Center for Mind, Brain, and Cognitive Evolution, Ruhr Universität Bochum, October 2016 - March 2017. Many thanks to Albert Newen and Shaun Gallagher for making this visit possible!

\section{References}

Beilock, S. L., \& Carr, T. H. (2001). On the fragility of skilled performance: What governs choking under pressure? Journal of Experimental Psychology: General, 130(4), 701-725.

Beilock, S. L., Carr, T. H., MacMahon, C., \& Starkes, J. L. (2002). When Paying Attention becomes Counterproductive: Impact of Divided versus Skill-focused Attention on Novice and Experienced Performance of Sensorimotor Skills. Journal of Experimental Psychology: Applied, 8(1), 6-16.

Cappuccio, M. (2015). Special issue: Unreflective action and the choking effect. Phenomenology and the Cognitive Sciences, 14(2), 213-431.

Dreyfus, H. L. (2012). Overcoming the myth of the mental. Topoi, 25(1-2), 43-49.

Enoka, R. M. (1988). Muscle strength and its development. Sports Medicine, 6, 146. doi:10.2165/00007256198806030-00003.

Fridland, E. (2014a). They've lost control: Reflections on skill. Synthese, 91(12), 2729-2750.

Fridland, E. (2015). Automatically minded. Synthese, Online First, doi:10.1007/s11229-014-0617-9.

Gallagher, S. 2005. How the Body Shapes the Mind. New York: Oxford University Press.

Hameed, M., et al. (2016). Muscle mania: The quest for the perfect body, BMJ Case Reports, published online 1 December 2016, doi:10.1136/bcr-2016-217208.

Hodson-Tole, E. F., \& Wakeling, J. M. (2009). Motor unit recruitment for dynamic tasks: Current understanding and future directions. Journal of Comparative Physiology. B, 179(1), 57-66.

Kirkkopelto, E. (2015). For what do we need performance philosophy. Performance Philosophy, 1(1), 4-6.

Krüger, H.-P. (2010). Persons and their bodies: The Körper/Leib distinction and Helmuth Plessner's theories of ex-centric positionality and Homo absconditus. Journal of Speculative Philosophy, 24(3), 256-274.

Legrand, D. (2010). Myself with no body? Body, bodily-consciousness, and self-consciousness. In S. Gallagher \& D. Schmicking (Eds.), Hanbook of phenomenology and cognitive science (pp. 181-200). Dordrecht: Springer.

McBride, F. (1975). Toward a non-definition of sport. Journal of the Philosophy of Sport, 2(1), 4-11.

Merleau-Ponty, M. (1962). Phenomenology of Perception, (transl. C. Smith) London: Routledge and Kegan Paul.

Montero, B. (2010). Does bodily awareness interfere with highly skilled movement? Inquiry, 53(2), 105-122.

Morgan, W. J. (1977). Some Aristotelian notes on the attempt to define sport. Journal of the Philosophy of Sport, 4(1), 15-35.

Murphy, J. S. (Ed.). (1999). Feminist interpretations of Jean-Paul Sartre. University Park: Pennsylvania State University Press.

Noë, A. (2012). Varieties of presence. Cambridge: Harvard University Press.

Rizzolatti, G. 2004. The mirror-neuron system. Annual Review of Neuroscience 27, 169-192.

Sartre, J-P. (1943). Being and Nothingness, (transl. H. E. Barnes) New York NY: Washington Square Press.

Wakeling, J. M., Lee, S. S. M., Arnold, A. S., de Boef Miara, M., \& Biewener, A. A. (2012). A Muscle's force depends on the recruitment patterns of its fibers. Annals of Biomedical Engineering, 40(8), 1708-1720. doi:10.1007/s10439-012-0531-6.

Williams, J. M. (Ed.). (1993). Applied sport psychology: Personal growth to peak performance. Mountain View: Mayfield Pub Co.. 